\title{
Predição de Curvas de Crescimento de Tecidos de Fêmeas Suínas por Intermédio da Função Alométrica Estendida ${ }^{1}$
}

\author{
Wilson Moreira Dutra Jr. ${ }^{2}$, Aloízio Soares Ferreira ${ }^{3}$, Juarez Lopes Donzele ${ }^{3}$, \\ Ricardo Frederico Euclydes ${ }^{3}$, Jaime Urdapilleta Tarouco ${ }^{4}$, Leandro Lunardini Cardoso 5
}

\begin{abstract}
RESUMO - Foram utilizadas 48 fêmeas suínas para se determinarem as curvas de crescimento de tecidos, após abate e dissecação das carcaças dos animais aos 50,60, 70, 80, 90,100,110 e $120 \mathrm{~kg}$. Os cortes realizados nas carcaças foram feitos de acordo com aqueles utilizados pela indústria. Em cada corte, separaram-se as quantidades de músculo, gordura, ossos e pele, para o cálculo de rendimento de tecidos. Foi utilizada a função alométrica estendida, para estimar e ajustar as curvas de crescimento. A quantidade de músculo na carcaça apresentou crescimento variando de 41,9 nos animais de $50 \mathrm{~kg}$, a 44,1\%, nos animais de $120 \mathrm{~kg}$. A função alométrica estendida ajustou a curva para quantidade de músculo, com $\mathrm{R}^{2}=0,68$ e desvio-padrão residual de 1,42 . Os valores de $\mathrm{R}^{2}$ para porcentagem de gordura foram de 0,80 e os de desvio-padrão residual, de 6,35, com aumento de 12,7 a 18,3\% entre 50 e $120 \mathrm{~kg}$. Quanto às curvas de crescimento para rendimento de cortes comerciais, os valores de $\mathrm{R}^{2}$ foram variáveis, porém com desvios-padrão residuais baixos. Concluiu-se que a função alométrica estendida é acurada para estimar curvas de crescimento de tecidos calculados, em porcentagens do peso de suínos vivos abatidos entre 50 e $120 \mathrm{~kg}$ de peso corporal; a deposição de gordura é proporcionalmente maior que a deposição de tecido muscular; e os suínos depositam, em termos proporcionais, tecido muscular e gordura de forma crescente.
\end{abstract}

Palavras-chave: cortes cárneos, curvas de crescimento, função alométrica estendida, suínos

\section{Prediction of Tissue Growth Curves of Female Pork by the Expanded Allometric Function}

Abstract - Forty-eight female pigs were used to determine tissue growth curves after slaughter of the animals at 50, 60, 70, 80, 90, 100,110 and $120 \mathrm{~kg}$ and dissection of the carcasses. The lean cuts in carcass were made according to that used by Brazilian pork slaughters. In each cut it were separated muscle, fat, bone and skin amounts. The expanded allometric function was used to estimate and to fit the growth curves. The muscle amounts in carcass increased to $41.9 \%$ for animals at $50 \mathrm{~kg}$ and to $44.1 \%$ for animals at $120 \mathrm{~kg}$. The expanded allometric function fitted the curve to muscle amount with $\mathrm{R}^{2}=0.68$ and the residual standard deviation $\mathrm{RSD}=1.82$. The $\mathrm{R}^{2}$ value for fat percentage was $0.80 \%$ and the (RSD) value was 6.35 with increase of $12.7 \%$ to $18.3 \%$ between animals at 50 to $120 \mathrm{~kg}$. Concerning to the growth curves for the commercial meat cut yields, the $\mathrm{R}^{2}$ value was variable, although with a RSD low. It was concluded that the expanded allometric function is accurate to estimate swine time growth curves calculated in percentage of weight of swine, slaughter between 50 and $120 \mathrm{~kg}$ and that fat deposition is proportionally higher than muscle deposition and that muscle and fat deposition, in percentage of carcass, increase from 50 to $120 \mathrm{~kg}$.

Key Words: expanded allometric function, growth curves, meat cuts, swine

\section{Introdução}

O estudo do crescimento, por meio de ajustamento de uma função que descreva todo o período de vida do animal, relacionando peso e idade tem sido pesquisado por vários autores. Têm sido propostos diversos modelos para explicar o crescimento biológico dos animais, como as funções Brody, Logística, Gompertz, Bertalanffy (FITZHUGH JR., 1976).

No caso de suínos, têm-se desenvolvido vários estudos sobre as curvas de crescimento, já que o melhoramento genético, aliado às pesquisas nutricionais, pode alterar o comportamento biológico do crescimento desses animais. ALVES (1986) considerou o modelo Brody o de pior ajuste, tanto do ponto de vista biológico, como estatístico, para se ajustar a curva de crescimento de suínos. Por outro lado, FREITAS e COSTA (1983) e RODRIGUES et al. (1992), estudando as diferentes funções (Logística, Gompertz, Bertalanffy e Richards), para se estimarem as curvas de crescimento de suínos, do nascimento ao abate, conclu-

\footnotetext{
${ }^{1}$ Parte da tese apresentada à UFV para obtenção do título de "Doctor Scientiae."

2 Professor da FZVA/PUCRS. E.mail: wmd@pucrs.campus2.br

3 Professor do DZO/UFV.

4 Zootecnista, Doutorando UFRGS.

5 Zootecnista, Bolsista de Aperfeiçoamento/FAPEMIG.
} 
íram que todos os modelos tiveram bom ajuste dos dados, com altos valores de $\mathrm{R}^{2}$.

A deposição de tecidos, principalmente de músculo e gordura, nos cortes cárneos dos suínos, tem gerado grande interesse, uma vez que esses dois componentes podem determinar o valor econômico do animal (AKRIDGE et al., 1992). Porém, verifica-se controvérsia com relação às formas de se estimarem curvas de crescimento do tecido animal, encontrando-se poucos resultados de pesquisa com relação à dissecação de carcaças de suínos.

Estudos envolvendo o rendimento de carne magra e a otimização de curvas de crescimento foram realizados por diversos autores, WILLIAMS et al. (1994), WHITE et al. (1995) e FIALHO et al. (1998), os quais verificaram correlações negativas entre os crescimentos de músculo e gordura nas carcaças de suínos, porém os fatores nutricionais podem estar relacionados com a deposição de tecidos (FRIESEN et al., 1996; SCHINCKEL e LANGE, 1996), bem como os fatores genéticos podem interferir nos parâmetros de crescimento dos tecidos (THOMPSOM et al., 1996).

Estudos realizados por WAGNER et al. (1999), com diferentes funções para estimar mudanças na composição corporal de suínos, demonstraram que a função alométrica estendida foi a mais acurada para estimar o crescimento de partes dos diferentes tecidos nos cortes das carcaças de suínos.

Quantificar e estimar o crescimento de tecidos, muscular, gorduroso, ósseo e de pele de suínos, por intermédio dos resultados da dissecação das carcaças, para predizer curvas de crescimento de tecidos de suínos entre 50 e $120 \mathrm{~kg}$, por meio da função alométrica estendida, foram os objetivos pretendidos com a realização desta pesquisa.

\section{Material e Métodos}

Foram selecionadas quarenta e oito fêmeas suínas de um grupo de 500, da linhagem Camborough 22, com peso médio inicial de $25,53 \mathrm{~kg}$ e idade média de 62 dias.

Os animais foram alojados, em 07 de agosto de 1998, nas instalações da granja multiplicadora da Cooperativa mista General Osório Ltda., em XV de Novembro, RS.

Os animais ficaram em observação por 32 dias, até atingirem média de 53,5 kg, quando seis animais foram abatidos. Após esse primeiro abate, foram selecionados seis animais, para abate aos 60, 70, 80, $90,100,110$ e $120 \mathrm{~kg}$.
Os animais foram alimentados com rações convencionais distribuídas aos cooperados da Cotribá.

Os animais foram abatidos no frigorífico da COOPERJACUÍ, Central de Cooperativas do Alto Jacuí. Após o período de resfriamento, que durou, no mínimo e máximo, 24 e 72 horas, respectivamente, à temperatura de $5 \mathrm{oC}$, foi realizada a dissecação das carcaças, utilizando-se somente a meia-carcaça esquerda, que foi separada em cortes cárneos, de acordo com os critérios adotados pela indústria, ou seja, foram separados os cortes cárneos paleta, pernil, copa, carré e barriga. Após essa separação, pesou-se cada parte em balança digital com precisão de $5 \mathrm{~g}$, que, após, foi dissecada da seguinte forma: 1 . separou-se a pele da gordura subcutânea; 2 . retiraram-se os ossos e, depois, separaram-se os músculos, removendo-se o máximo da gordura intermuscular; 3 . as fáceas e as aponeuroses dos músculo foram deixadas nos mesmos, separando-se também os gânglios; e 4. colocou-se cada porção de músculo, gordura, pele, ossos e gânglios em sacos plásticos, que foram pesados em balança digital, para o cálculo dos rendimentos de carne magra, porcentagem de gordura e porcentagem de ossos, além dos diversos cortes comerciais.

As curvas de crescimento de tecidos foram estimadas a partir dos dados resultantes da dissecação das carcaças, dos diferentes cortes comerciais, adotando-se a função alométrica estendida, conforme descrito por WAGNER et al. (1999), a qual é expressa como:

$\log _{10} Y=b_{0}+b_{1} \log _{10} x+b_{2} \log _{10}(k-x)$ em que: $b_{0}=$ variável indenpedente, sem interpretação biológica; $b_{1} \log _{10} \mathrm{x}=$ variável independente, sem interpretação biológica; $b_{2} \log _{10}(k-x)=$ variável independente, sem interpretação biológica; $\mathrm{K}=$ indice de maturidade; $\mathrm{X}=$ constante de integração.

Utilizou-se o procedimento Guauss-Newton, por meio de regressões não-lineares. Pacote SAEG, (1998)

\section{Resultados e Discussão}

As médias de peso e porcentagens de tecidos nas carcaças estão apresentadas na Tabela 1. Pode-se verificar que o tecido muscular apresentou crescimento percentual, que variou de 41,9 a $44,1 \%$, enquanto a porcentagem de gordura, valores variáveis entre 12,7 e $18,3 \%$, aos 50 e $120 \mathrm{~kg}$, respectivamente.

IRGANG e PROTAS (1986) encontraram valores de 28,7 a 34,7\% e FIALHO et al. (1998), de 26,8 a $28,8 \%$, para porcentagem de gordura, para pesos de 
Rev. bras. zootec.

Tabela 1 - Peso e porcentagens de tecidos nas carcaças, em relação ao peso dos suínos vivos

Table 1 - Carcasses tissues weight and percentage in relation to swine live weights

\begin{tabular}{|c|c|c|c|c|c|c|c|c|c|}
\hline $\begin{array}{l}\text { Peso } \\
\text { abate } \\
(\mathrm{kg})\end{array}$ & $\begin{array}{l}\text { Idade } \\
\text { média } \\
\text { (dias) }\end{array}$ & $\begin{array}{l}\text { Peso } \\
\text { músc. } \\
(\mathrm{kg})\end{array}$ & $\begin{array}{l}\text { Porc. } \\
\text { músc. } \\
(\%)\end{array}$ & $\begin{array}{l}\text { Peso } \\
\text { gord. } \\
(\mathrm{kg})\end{array}$ & $\begin{array}{c}\text { Porc. } \\
\text { gord. } \\
(\%)\end{array}$ & $\begin{array}{c}\text { Peso } \\
\text { ossos } \\
(\mathrm{kg})\end{array}$ & $\begin{array}{l}\text { Porc. } \\
\text { ossos } \\
(\%)\end{array}$ & $\begin{array}{l}\text { Peso } \\
\text { pele } \\
(\mathrm{kg})\end{array}$ & $\begin{array}{l}\text { Porc. } \\
\text { pele } \\
(\%)\end{array}$ \\
\hline $\begin{array}{l}\text { Slaughter } \\
\text { weight }\end{array}$ & $\begin{array}{c}\text { Average } \\
\text { age (days) }\end{array}$ & $\begin{array}{c}\text { Muscle } \\
\text { weight }\end{array}$ & $\begin{array}{c}\text { Muscle } \\
\text { perc. }\end{array}$ & $\begin{array}{c}\text { Fat } \\
\text { weight }\end{array}$ & $\begin{array}{c}\text { Fat } \\
\text { perc. }\end{array}$ & $\begin{array}{c}\text { Bone } \\
\text { weight }\end{array}$ & $\begin{array}{l}\text { Bone } \\
\text { perc. }\end{array}$ & $\begin{array}{c}\text { Skin } \\
\text { weight }\end{array}$ & $\begin{array}{l}\text { Skin } \\
\text { perc. }\end{array}$ \\
\hline 50 & 94 & 21,00 & 41,9 & 6,37 & 12,7 & 5,25 & 10,5 & 2,90 & 5,8 \\
\hline 60 & 106 & 25,01 & 42,3 & 9,59 & 16,2 & 6,40 & 10,8 & 2,75 & 4,6 \\
\hline 70 & 110 & 29,31 & 41,7 & 11,18 & 15,9 & 7,74 & 11,0 & 2,83 & 4,0 \\
\hline 80 & 128 & 33,85 & 42,5 & 14,26 & 17,9 & 8,94 & 11,2 & 3,19 & 4,0 \\
\hline 90 & 141 & 38,31 & 42,2 & 16,89 & 18,6 & 10,11 & 11,1 & 3,47 & 3,9 \\
\hline 100 & 154 & 44,54 & 44,0 & 18,38 & 18,2 & 11,68 & 11,6 & 4,00 & 4,0 \\
\hline 110 & 159 & 47,03 & 43,4 & 19,72 & 18,2 & 12,16 & 11,2 & 3,79 & 3,5 \\
\hline 120 & 170 & 53,65 & 44,1 & 22,28 & 18,3 & 14,23 & 11,7 & 4,15 & 3,5 \\
\hline
\end{tabular}

abate entre 80 e $120 \mathrm{~kg}$, porém, em ambos, as pesquisas foram conduzidas com base no peso de carcaça, o que pode explicar as diferenças nos resultados, uma vez que, neste estudo, levou-se em conta o peso do animal vivo.

No cálculo do rendimento, considerando-se o peso da carcaça quente, verificou-se que a porcentagem da gordura variou de 17,9 a $23,7 \%$ e em relação à carcaça fria, de 18,2 a 24,2\%. Estes valores ainda foram inferiores aos encontrados por IRGANG e PROTAS (1986).

A relação carne:gordura pode ser indicativo da proporção desses dois tecidos na carcaça, passando de 1:0,30, aos $50 \mathrm{~kg}$ de peso corporal, para 1: 0,42 , aos $120 \mathrm{~kg}$ de peso corporal, evidenciando que os animais tenderam a acumular mais gordura, à medida que aumentou o peso de abate. Estes resultados estão de acordo com os apresentados por SATHER et al. (1996), que obtiveram valores médios de 49,7\% de rendimento de carne para fêmeas, porém, em relação à carcaça fria. IRGANG et al. (1998) encontraram valores de $49,47 \%$ para rendimento de carne, também em relação ao peso de carcaça.

Verificou-se, por intermédio da comparação dos resultados encontrados nas diversas pesquisas, que a quantidade de tecidos tem sido variável em função da metodologia utilizada. Nesta pesquisa, o cálculo do rendimento de músculo foi feito em relação ao peso do animal vivo; porém, pode-se observar que os valores encontrados para rendimento de carne foram superiores àqueles obtidos por IRGANG e PROTAS (1986), os quais calcularam o rendimento com base na carcaça inteira e encontraram valores entre 41,2 e $46 \%$.

Quanto aos valores percentuais de ossos e pele, observou-se aumento de ordem de $1 \%$, na porcenta- gem de ossos entre 50 e $120 \mathrm{~kg}$; todavia, com relação à pele, observou-se o inverso, tendo ocorrido diminuição da porcentagem de pele na carcaça, à medida que aumentou o peso corporal, variando de 5,8 , aos $50 \mathrm{~kg}$, a $3,5 \%$, aos $120 \mathrm{~kg}$.

Analisando-se as variações do crescimento dos diversos tecidos, constatou-se que o aumento percentual do tecido gorduroso foi maior que o do tecido muscular; a porcentagem de osso se manteve estável; e a pele diminuiu percentualmente para os animais abatidos entre 50 e $120 \mathrm{~kg}$ de peso vivo.

Na Tabela 2, estão apresentados os pesos e as porcentagens de músculo nos cortes comerciais pernil, paleta, carré, copa e barriga, a partir dos quais pode-se verificar que o corte com maior quantidade de carne foi o pernil, ocorrendo ligeiro aumento percentual de 12,6 a $13,0 \%$, para animais abatidos entre 50 e $120 \mathrm{~kg}$. Fato semelhante foi observado por FORTIN (1980), que verificou variação de 16,84 a $17,07 \%$ de fêmeas abatidas entre 85 e $112 \mathrm{~kg}$ de peso corporal, em relação ao peso da carcaça fria. Já IRGANG e PROTAS (1986) observaram que a porcentagem de carne no pernil, em relação ao peso do corte, diminuiu de 65,3 para $59,2 \%$, em animais com pesos de 80 a $140 \mathrm{~kg}$. WAGNER et al. (1999) encontraram valores muito semelhantes para peso $\mathrm{e}$ porcentagem de músculo no pernil, com valores percentuais médios de $11,4 \%$ para fêmeas com pesos entre 64 e $129 \mathrm{~kg}$.

Verificou-se, com relação ao corte paleta, constância no valor percentual entre os 50 e $120 \mathrm{~kg}$ de peso corporal, em torno dos 9,5\%. Estes resultados estão de acordo com aqueles encontrados por MACHADO et al. (1984), que verificaram valores constantes no teor de carne na paleta de animais abatidos 
entre 100 e $140 \mathrm{~kg}$ de peso vivo. IRGANG e PROTAS (1984) observaram diminuição no valor percentual de carne na paleta, nos animais abatidos entre 80 e $140 \mathrm{~kg}$ de peso vivo; a mesma tendência foi também verificada por WAGNER (1999), em animais abatidos entre 25 e $152 \mathrm{~kg}$ de peso corporal.

No que diz respeito à quantidade de músculo no carré, na copa e barriga, verificou-se relação inversa, tendo sido constatado aumento das porcentagens de músculo, à medida que aumentou a idade do animal. No corte carré, o aumento foi de 9 para $10 \%$ de músculo para fêmeas abatidas entre 50 e $120 \mathrm{~kg}$ de peso vivo. Estes resultados diferem daqueles encontrados por IRGANG et al. (1984), que verificaram diminuição nas porcentagens de carne nesse corte em animais abatidos entre 80 e $140 \mathrm{~kg}$ de peso vivo.

Entretanto, os resultados deste estudo foram semelhantes aos observados por FORTIN (1980), que encontrou valores percentuais de músculo no lombo, em relação ao peso da carcaça fria, de 19,60; 20,68; 22,93; e 21,08 para fêmeas abatidas aos 85, 92, $103 \mathrm{e}$ $112 \mathrm{~kg}$, e aos obtidos por WAGNER et al. (1999), que também observaram aumento na porcentagem de músculo do lombo para animais abatidos entre $25 \mathrm{e}$ $152 \mathrm{~kg}$ de peso corporal.

Verificou-se que o corte do carré superou o corte da paleta, em quantidade e porcentagem de músculo, nos animais abatidos a partir dos $90 \mathrm{~kg}$ e a deposição do tecido muscular continuou crescendo nos cortes comerciais até os $120 \mathrm{~kg}$ de peso corporal, com exceção da paleta.

Os valores de peso e porcentagens de gordura nos cortes comerciais, em relação ao peso vivo de 50 a $120 \mathrm{~kg}$, podem ser visualizados na Tabela 3 , na qual se constata que houve aumento na porcentagem de gordura nos cortes, à medida que aumentou o peso de abate, com exceção no corte copa, em que a porcentagem de gordura se manteve constante em torno de $0,6 \%$. O corte que apresentou a maior quantidade de gordura foi a paleta, com média de $5,4 \%$ de gordura, em relação ao peso do animal vivo; em segundo lugar, tém-se o corte barriga com $4,5 \%$, seguido pelo carré, com $3,6 \%$, e o pernil, com $3,0 \%$ de gordura.

$\mathrm{O}$ aumento da porcentagem de gordura verificado nos cortes comerciais, neste estudo, está de acordo com aqueles obtidos por MACHADO et al. (1984) e FIALHO et al. (1998).

Analisando os dados contidos nas Tabelas 2 e 3, pode-se observar que os cortes de maior rendimento de carne magra na carcaça de fêmeas suínas abatidas entre 50 e $120 \mathrm{~kg}$ de peso vivo foram o pernil e o

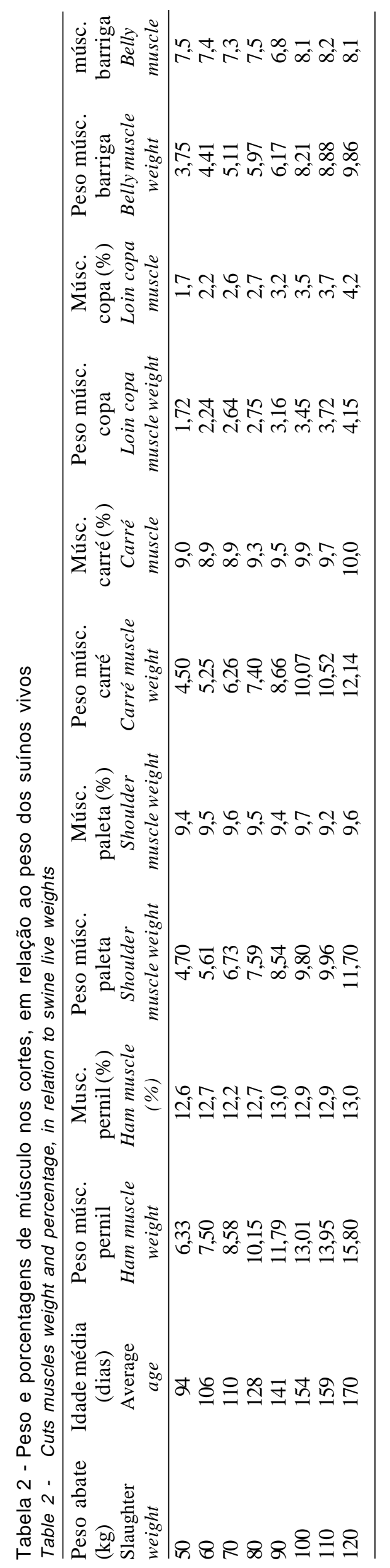




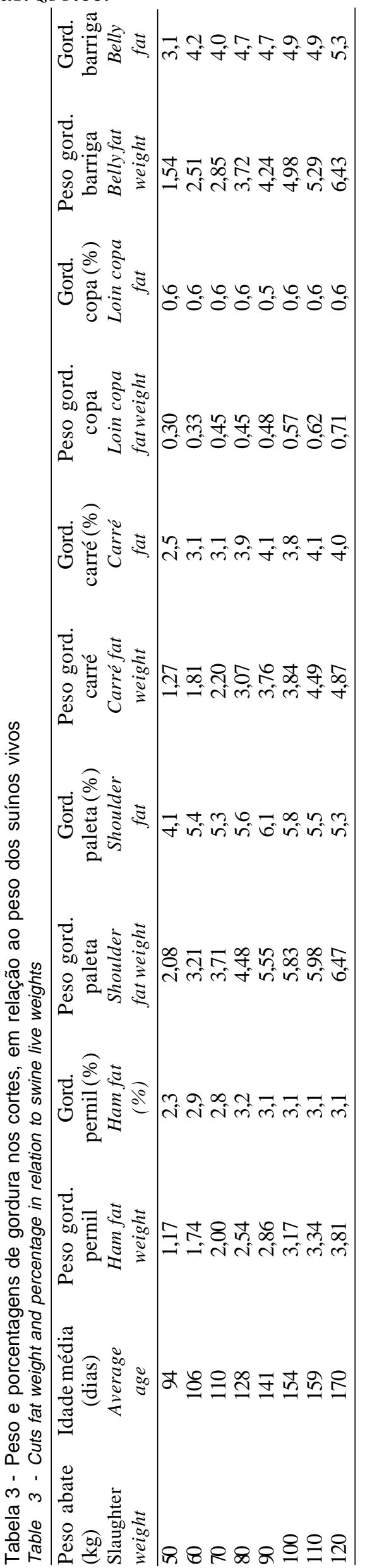

carré. A paleta e a barriga equivaleram-se na relação carne:gordura, porém, vale ressaltar a dificuldade de separar gordura de carne no corte barriga.

Nas Tabelas 4 e 5, estão apresentados os resultados relativos a quantidades e porcentagens de ossos e pele nos cortes comerciais dos suínos. A partir destes resultados, observou-se que a porcentagem de ossos e pele tendeu a diminuir nos cortes comerciais para os animais abatidos entre 50 e 120 $\mathrm{kg}$. Os cortes que apresentaram a maior quantidade de ossos foram o pernil e o carré, com valores percentuais médios de $2,2 \%$, com a ressalva de que o carré suplantou o pernil em quantidade de ossos a partir dos $90 \mathrm{~kg}$ de peso corporal.

Observou-se, também, que a porcentagem média de ossos na carcaça, em relação ao peso vivo, foi de $11,10 \%$. Este valor está em consonância com os resultados observados por MACHADO et al. (1984) e IRGANG et al. (1998).

$\mathrm{Na}$ literatura, existem poucos dados em relação à pele. Nesta pesquisa, verificou-se que a porcentagem de pele diminuiu nos cortes, à medida que aumentou o peso corporal. IRGANG e PROTAS (1986) e WAGNER et al., (1999) verificaram a mesma tendência de queda na porcentagem de pele na carcaça com animais abatidos em outras faixas de peso.

$\mathrm{Na}$ Figura 1, estão apresentadas as curvas de crescimento de tecidos de suínos, com pesos de abate entre 50 e $120 \mathrm{~kg}$. A função alométrica estendida ajustou curvas para músculo, gordura, ossos e pele, com R2 de 0,$68 ; 0,80 ; 0,86$; e 0,74 e desvio-padrão residual de 1,$42 ; 6,35 ; 0,49 ;$ e 1,03 , respectivamente.

Verificou-se que a curva de crescimento de gordura foi mais acentuada que a dos demais tecidos, havendo aceleramento até os $80 \mathrm{~kg}$, tendendo a se estabilizar em torno de $18 \%$ após os $90 \mathrm{~kg}$. Quanto ao tecido muscular, o aumento foi gradativo e constante, porém em menor velocidade a partir dos $100 \mathrm{~kg}$ de peso vivo. $\mathrm{O}$ crescimento do tecido ósseo mantevese estável e o crescimento de pele apresentou curva decrescente dos 50 aos $120 \mathrm{~kg}$ de peso corporal.

FIALHO et al. (1998), ao estabelecerem curvas de crescimento para porcentagem de gordura e porcentagem de carne magra, com efeitos quadrático e linear e R2 de 0,97 e 0,76, respectivamente (os autores não informaram os valores de desvio-padrão residual), concluíram que, enquanto a porcentagem de carne diminuiu a partir dos $100 \mathrm{~kg}$, a gordura continuou aumentando até os $120 \mathrm{~kg}$.

Estudos realizados por WAGNER et al. (1999), utilizando a função alométrica estendida, observaram 
1012

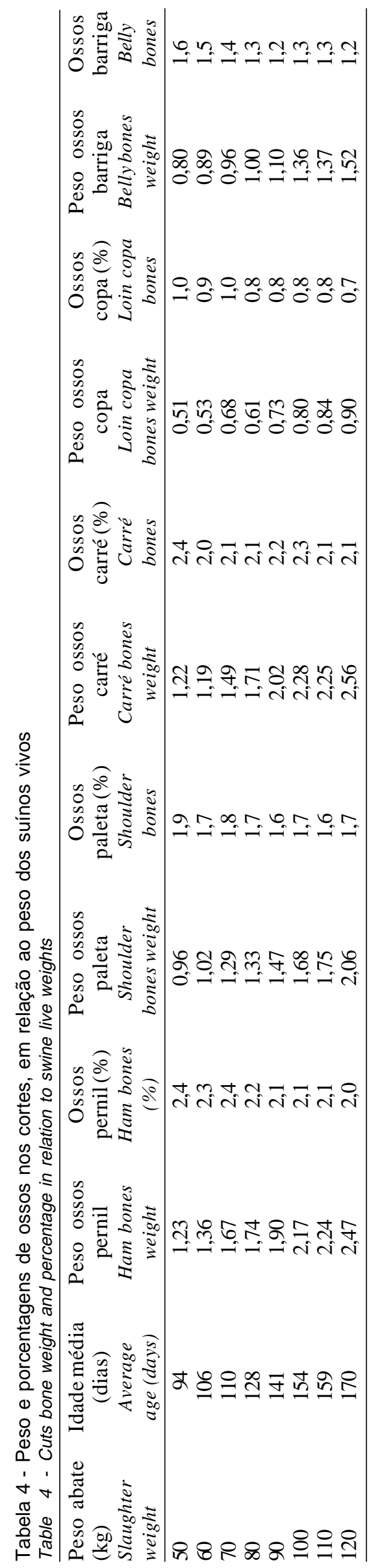

DUTRA JR. et al.

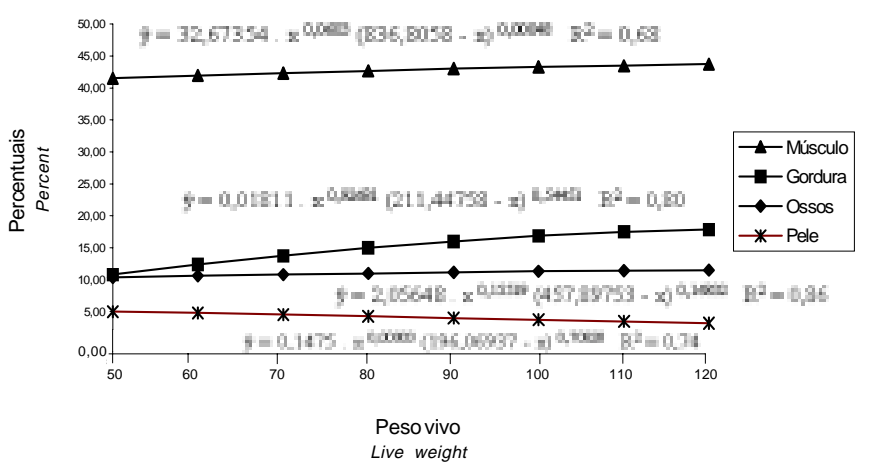

Figura 1 - Curvas de crescimento de tecidos de suínos abatidos entre 50 e $120 \mathrm{~kg}$ de peso corporal.

Figure 1 - Tissues growth curves of swines slaughtered from 50 to $120 \mathrm{~kg}$ body weight.

que a relação ganho de carne magra/ganho de peso corporal aumentou até os $65 \mathrm{~kg}$, diminuindo a partir dos $65 \mathrm{~kg}$ até o peso de abate, aos $154 \mathrm{~kg}$.

A partir das curvas de crescimento do tecido de músculo e gordura, nos corte pernil e carré (cortes com maiores quantidades de músculo na carcaça), que estão apresentados nas Figuras 2 e 3, pode-se observar que a velocidade de crescimento do músculo do carré foi mais acentuada que a do pernil, com aumento de $1,0 \%$ para o carré, enquanto o crescimento percentual do músculo do pernil foi de $0,4 \%$ e a curva de crescimento do tecido gorduroso do carré, mais acentuada que a curva de gordura do pernil, demonstrando que o corte do carré tendeu a acumular mais gordura até os $120 \mathrm{~kg}$ de peso corporal que o corte pernil.

Estes valores foram semelhantes àqueles observados por WAGNER et al. (1999), que abateram suínos entre 25 e $152 \mathrm{~kg}$ de peso corporal. FORTIN (1980) também observou ligeiro aumento nas porcentagens de músculo do lombo e diminuição na porcentagem de carne do pernil, em fêmeas abatidas entre 85 e $112 \mathrm{~kg}$.

MACHADO et al. (1984) observaram que a porcentagem de carne no pernil não se elevou com o aumento do peso de abate de suínos dos 100 aos 140 kg. Já IRGANG e PROTAS (1986) observaram diminuição das porcentagens de carne tanto no corte pernil, quanto no carré, em suínos abatidos entre 80 e $140 \mathrm{~kg}$ de peso vivo.

Nesta pesquisa, verificou-se que o pernil apresentou tendência de estabilização do crescimento de gordura a partir dos $100 \mathrm{~kg}$ de peso vivo, sendo que os valores observados foram semelhantes aos estima- 
Rev. bras. zootec.

Tabela 5 -Peso e porcentagens de pele de cortes, em relação ao peso dos suínos vivos Table 5 - Cuts skin weight and percentage in relation to swine live weights

\begin{tabular}{|c|c|c|c|c|c|c|c|c|c|}
\hline $\begin{array}{l}\text { Peso } \\
\text { abate } \\
(\mathrm{kg}) \\
\text { Slaughter } \\
\text { weight }\end{array}$ & $\begin{array}{c}\text { Idade } \\
\text { média } \\
\text { (dias) } \\
\text { Average } \\
\text { age (days) }\end{array}$ & $\begin{array}{c}\text { Peso } \\
\text { pele } \\
\text { pernil } \\
\text { Han skin } \\
\text { weight }\end{array}$ & $\begin{array}{c}\text { Pele } \\
\text { pernil } \\
(\%) \\
\text { Ham skin } \\
(\%)\end{array}$ & $\begin{array}{c}\text { Peso } \\
\text { pele } \\
\text { paleta } \\
\text { Shoulder skin } \\
\text { weight }(\%)\end{array}$ & $\begin{array}{c}\text { Pele } \\
\text { paleta } \\
(\%) \\
\text { Shoulder } \\
\text { skin }\end{array}$ & $\begin{array}{c}\text { Peso } \\
\text { pele } \\
\text { carré } \\
\text { Carré skin } \\
\text { weight }\end{array}$ & $\begin{array}{l}\text { Pele } \\
\text { carré } \\
(\%) \\
\text { Carré } \\
\text { skin }\end{array}$ & $\begin{array}{l}\text { Peso } \\
\text { pele } \\
\text { barriga } \\
\text { Belly skin } \\
\text { weight }\end{array}$ & $\begin{array}{c}\text { Pele } \\
\text { barriga } \\
(\%) \\
\text { Belly } \\
\text { Skin (\%) }\end{array}$ \\
\hline 50 & 94 & 0,73 & 1,5 & 1,09 & 2,2 & 0,37 & 0,74 & 0,71 & 1,4 \\
\hline 60 & 106 & 0,68 & 1,1 & 0,97 & 1,6 & 0,43 & 0,72 & 0,69 & 1,2 \\
\hline 70 & 110 & 0,67 & 0,9 & 0,96 & 1,4 & 0,46 & 0,66 & 0,75 & 1,1 \\
\hline 80 & 128 & 0,72 & 0,9 & 1,02 & 1,3 & 0,58 & 0,73 & 0,86 & 1,1 \\
\hline 90 & 141 & 0,83 & 0,9 & 1,09 & 1,2 & 0,63 & 0,70 & 0,92 & 1,0 \\
\hline 100 & 154 & 0,94 & 0,9 & 1,28 & 1,3 & 0,71 & 0,70 & 1,08 & 1,1 \\
\hline 110 & 159 & 0,87 & 0,8 & 1,22 & 1,1 & 0,71 & 0,66 & 0,99 & 0,9 \\
\hline 120 & 170 & 0,99 & 0,8 & 1,23 & 1,0 & 0,78 & 0,64 & 1,16 & 1,0 \\
\hline
\end{tabular}

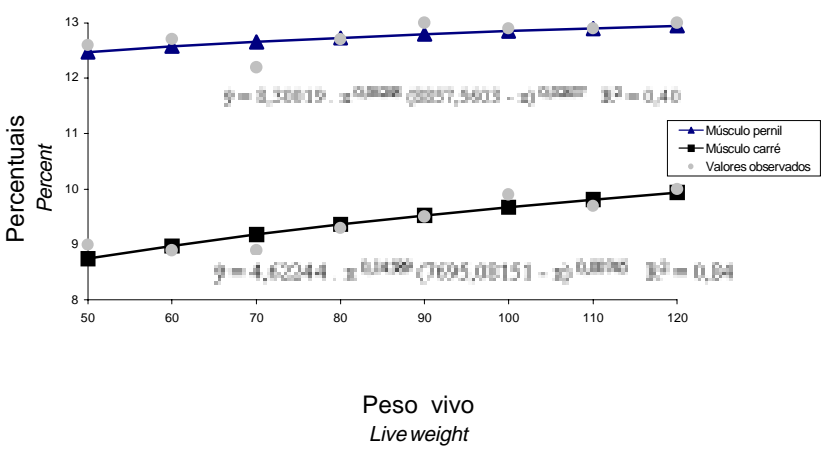

Figura 2 - Curvas de crescimento de tecido muscular nos cortes do pernil e do carré.

Figure 2 - Muscle tissue growth curves in the ham and carré cuts.

dos, o que pode suportar a tese de que o ajuste da função alométrica estendida explica o crescimento percentual de tecidos nos cortes pernil e carré.

As equações de predição elaboradas a partir da função alométrica estendida para os demais tecidos da carcaça de suínos apresentaram valores de $\mathrm{R}^{2}$ variáveis, conforme o tecido analisado, e melhores ajustes para porcentagens de gordura, ossos e pele e piores para porcentagem de músculo nos cortes comerciais.

\section{Conclusões}

Dos 50 aos $120 \mathrm{~kg}$, os suínos depositam, em termos proporcionais, tecido muscular e gordura de forma crescente.

Dos 50 aos $120 \mathrm{~kg}$, a proporção de ossos se mantém praticamente inalterada a de pele se reduz

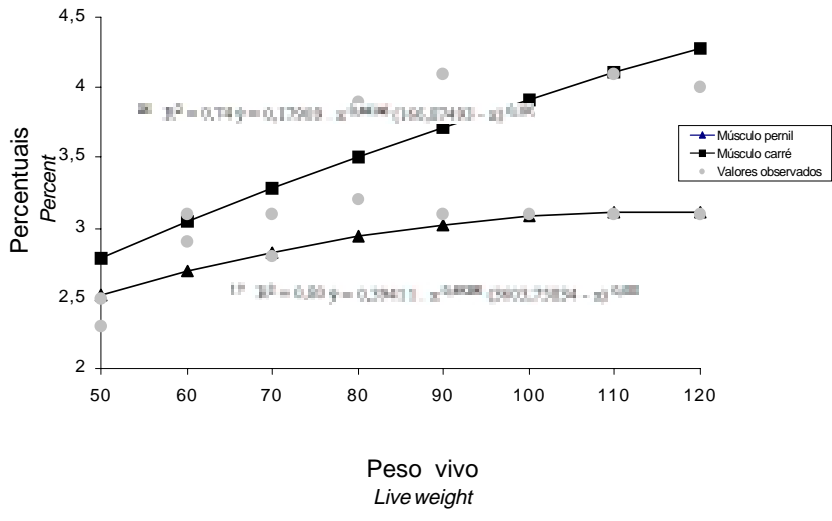

Figura 3 - Curvas de crescimento de gordura nos cortes do pernil e do carré.

Figure 3 - Fat growth curves in ham and carré cuts.

levemente e proporcionalmente a deposição de gordura é maior que a deposição de tecido muscular.

A função alométrica estendida, aplicada a porcentagens de tecidos, ajusta curvas de crescimento com boa acurácia, dependendo do tecido avaliado.

\section{Referências Bibliográficas}

AKRIDGE, J.J., BRORSEN, B.W., WHIPKER, L.D. et al. 1992. Evaluation of alternative techniques to determine pork carcass value. J. Anim. Sci., 70(1):18-28.

ALVES, R.G.O. Estudo genético de características reprodutivas em suínos e avaliação de curvas de crescimento em cruzamentos dialélicos. Viçosa, UFV, 1986. 126p. Tese (Doutorado em Zootecnia) - Universidade Federal de Viçosa, 1986.

CARR, T.R., WALTERS, L.E., WHITEMAN, J.V. 1978. Carcass composition changes in growing and finishing swine. J. Anim. Sci., 47(3):615-621.

EISEN, E.J. 1976. Results of growth curve in mice rats. J. Anim. Sci., 42(4):1008-1023.

FIALHO, E.T., OLIVEIRA, A.I.G., LIMA, J.A.F. et al. 1998 
Influência de planos de nutrição sobre as características de carcaça de suínos de diferentes genótipos, abatidos entre 80 e $120 \mathrm{~kg}$. R. Bras. Zootec., 27(6):1140-1146.

FITZHUGH JR., H.A. 1976. Analysis of growth curves and strategies for altering their shape. J. Anim. Sci., 42(4):1036-1051.

FORTIN, A. 1980. The effect of slaughter weight on the carcass characteristics of Yorkshire barrows and gilts. Can. J. Anim. Sci., 60(2):265-274.

FREITAS, A.R., COSTA, C.N. 1983. Ajustamento de modelos não lineares e dados de crescimento de suínos. Pesq. Agropec. Bras., 18(10):1147-1154.

FRIESEN, K.G., NELSSEN, J.C., GOODBAND, R.D. et al. 1996. The use of compositional growth curves for assessing the response to dietary lysine by high-lean growth gilts. Anim. Sci., 62(1):159-169.

GU, Y., SCHINCKEL, A.P., MARTIN, T.G. 1992. Growth, development and carcass composition in five genotypes of swine. J. Anim. Sci., 70(9):1719-1729.

HICKS, C.A., SCHINCKEL, A.P., FORREST, J.C. et al. 1998. Biases associated with genotype and Sex in prediction of fat free lean mass and carcass value in hogs. J. Anim. Sci., 76:2221-2234.

IRGANG, R., GUIDONI, A.L., BERLITZ, D. et. al. 1998. Medidas de espessura de toucinho e de profundidade de músculo para estimar rendimento de carne magra em carcaças de suínos. R. Bras. Zootec., 27(5):928-935.

IRGANG, R., PROTAS, J.F.S.1986. Peso ótimo de abate de suínos II. resultados de carcaça. Pesq. Agropec. Bras., 21(12):1337-1345.

MACHADO, D.P., NICOLAIEWSKY, S., FERNANDES, L.C.O. et al. 1984. Avaliação das carcaças de suínos abatidos com pesos elevados e submetidos a três regimes alimentares diferentes. R. Soc. Bras. Zootec., 13(3):316-323.

METZ, S.H., VERSTEGEN, M.W.A., WILDE, R.O. et al. 1984. Estimation of carcass and growth composition in the growing pig. Netherland J. Anim. Sci., 32(1):301-318.

MOUGHAN, P.J., SMITH, W.C., STEVENS, E.U.J. 1990. Allometric growth of chemical body components and several organs in the pig. New Zealand J. Agric. Res., 33(1):77-84.

OLIVEIRA, A.I.G., SILVA, M.A., TEIXEIRA, N.M. et al. 1988. Aspéctos genéticos das características das carcaças de suínos em cruzamentos dialélicos II. Características de classificação. R. Soc. Bras. Zootec., 17(6):535-543.

RODRIGUES, P.B., MUNIZ, J.A., PEREIRA, F.A. 1992. Estudo comparativo de curvas de crescimento em suínos. Ciência e Prática, 16(1):151-157.
SAFRANSKI, T.D., HARRIS, D.L., SCHINKEL, A.P. et al. 1995. Nonlinear prediction of carcass cutout for a swine simulation model. J. Anim. Sci., 73(supplement 1):141 (abstract).

SATHER, A.P., BAILEY, D.R.C., JONES, S.D.M. 1996. Realtime ultrasound image analysis for the estimation of carcass yield an pork quality. Can. J. Anim. Sci., 76(1):55-62.

SCHINCKEL, A.P., LANGE, C.F.M. 1996. Characterization of growth parameters needed as inputs for pig growth models. J. Anim. Sci., 74(10):2021-2036.

SHIELDS JR., R.G., MAHAN, D.C., GRAHAM, P.L. 1983. Changes in swine body composition from birth to $145 \mathrm{~kg}$. J. Anim. Sci., 57(1):43-54.

THOMPSON, J.M., SUN, F., KUCZEK, T. et al. 1996. The effect of genotype and sex on the patterns of protein accretion in pigs. Anim. Sci., 63(2):265-276.

UNIVERSIDADE FEDERAL DE VIÇOSA - UFV. 1998. SAEG - Sistema de análises estatísticas e genéticas. Versão 7.1. Viçosa, MG. 150p. (Manual do usuário).

WAGNER, J.R., SCHINCKEL, A.P., CHEN, W. et al. 1999. Analysis of body composition changes of swine during growth and development. J. Anim. Sci., 77:1442-1466.

WAGNER, J.R., SCHINKEL, A.P., FORREST, J.C. et al. 1992. Accuracy and biases in the estimation os fat free total carcass lean from electromagnetic scans of trimmed wholesale hams. J. Anim. Sci., 70(supplement 1):224 (Abstract).

WHITE, B.R., LAN, Y.H., McKEITH, F.K. et al. 1995. Growth and body composition of Meishan and Yorkshire barrows an gilts. J. Anim. Sci., 73(6):738-749.

WILLIAMS, N.H., CLINE, T.R., SCHINCKEL, A.P. et al. 1994. The impact of ractopamine, energy intake, and dietary fat on finisher pig growth performance and carcass merit. J. Anim. Sci., 72(12):3152-3162.

ZOBRINSKY, S.E., HUNZINGER, G.D., TRIBBLE, L.F. 1967. Longissimus muscle area development in swine. J. Anim. Sci., 26:470.

Recebido em: $27 / 09 / 00$

Aceito em: 06/03/01 